like it. The same can be said for biomolecular systems: we may never be able to comprehend every molecular interaction within a cell, but if we can build a system that behaves just like its natural counterpart, then perhaps we should be satisfied with that.

Amos's account of the different paths to synthetic biology covers most of the recent advances that have made the headlines. These range from pieces of DNA called 'biobricks' and the 'repressilator' to a way of coaxing yeast to produce the precursor for a malaria drug - a feat for which Jay Keasling, a biochemical engineer at the University of California, Berkeley, won Discover magazine's first 'scientist of the year' award.

But I have to take Amos to task for presenting the work of James Shapiro, a microbiologist at the University of Chicago, as if his investigations of the mechanisms of evolution somehow contradict darwinian evolution. Shapiro, who studies the many ways in which organisms can actively restructure their genetic material, believes that such processes should be more widely incorporated into evolutionary thinking. Although Darwin could not possibly have anticipated such processes, they follow the general darwinian paradigm and do not, in my opinion, necessitate a 'third way' somewhere between creationism and what Shapiro calls 'neo-darwinian orthodoxy'.

But apart from this quibble, this is an enjoyable book that could perhaps have profited from more illustrations to convey some of the computational and experimental methods. I recommend it to anyone interested in computation writ large who is not afraid to cross disciplinary boundaries that once seemed impassable.

Christoph Adami is at the Keck Graduate Institute of Applied Life Sciences, Claremont, California 91711, USA.

\title{
Mammals on the move
}

\section{The Beginning of the Age of Mammals by Kenneth D. Rose \\ Johns Hopkins University Press: 2006. 428 pp. $\$ 150$}

\section{Zofia Kielan-Jaworowska}

Just looking at The Beginning of the Age of Mammals by Kenneth Rose, with its Henri Rousseau-style jacket picture, catapults the reader right into enchanted Early Eocene life. The book is a scholarly treatment of an important period in the evolution of mammals. Mammals originated some 225 million years ago, and for about 160 million years they were small nocturnal creatures living in the shadow of the dinosaurs. Most of them would have been size of a shrew or rat, with only a few being as big as a fox. When the dinosaurs died out at the end of the Cretaceous, 65 million years ago, mammals changed lifestyle and started to increase their size, with many entering niches abandoned by the extinct giants. This was the age of mammals.

Kenneth Rose's book The Beginning of the Age of Mammals is devoted to this explosion of mammals, particularly their evolution during the first half of the Cenozoic period. Rose highlights in particular the development of placental mammals in the Palaeocene and Eocene (between 65 million and 33 million years ago).

One of the charms of this book is the abundance of figures, with many attractive reconstructions of Eocene mammals. Some of these have been made possible by the unusual preservation of complete mammalian skeletons from the Middle Eocene in Messel, Germany. Rose had an opportunity to collaborate with German colleagues when describing some of these mammals. As well as line drawings and black-and-white photographs, there are eight full-page colour plates with photographs of the best-preserved fossils and reconstructions.

Although the bulk of the book is devoted to this mammalian explosion, Rose starts at the beginning of the mammals' tale. Two introductory chapters are followed by four on the origin of mammals and their early evolution in the Mesozoic.

The author no doubt faced a problem when dividing the rest of the book into chapters. Details about the roots of many groups are hazy, and the earliest representatives of most

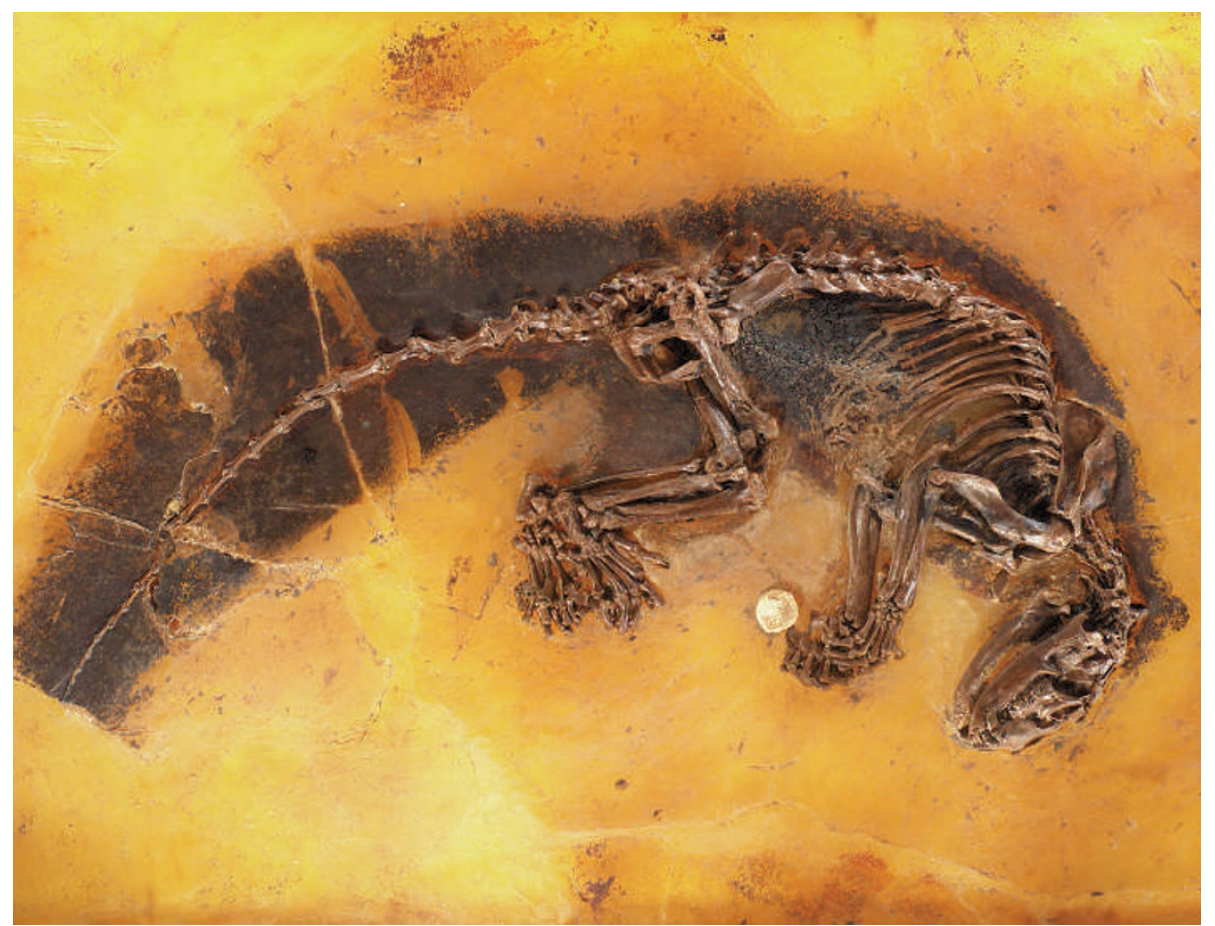

Fossil skeletons of Middle Eocene mammals such as Kopidodon have been found in Messel, Germany. orders are unknown, so it would be impossible to restrict the contents of chapters to strictly monophyletic units. Nowadays, taxonomists have to deal with two different taxonomies: a traditional one, based on morphology, and a modern one, based on molecular analysis. Each chapter begins with an introduction describing our changing views on the relationships of the animals to be discussed. These introductions show the perspective and knowledge that Rose uses when examining the data. When available, he provides two alternative cladograms showing the relationships among the studied forms, one based on morphology, the other on molecular studies. His preference is decidedly morphological, as is evident from his attitude to the clade Afrotheria.

The notion of Afrotheria arose around 1990, based on DNA analyses demonstrating that six living orders of African placental mammals form a monophyletic clade. Although Rose often mentions the Afrotheria, he states: "No morphological evidence supporting Afrotheria has been found." However, the Cretaceous representatives of modern mammalian orders are unknown, and the lack of an early fossil record for most groups may be responsible for any morphological gaps between them. Among the groups assigned to Afrotheria, Rose, on the basis of morphology, accepts the monophyly of Hyracoidea, Elephantoidea and Sirenia. But, against the molecular evidence, he assigns Tenrecidae and Chrysochloridae not to Afrosoricida but to Insectivora; Macroscelidea to the relatives of the Anagalida; and finally Tubulidentata (not described because of a lack of fossils) to the archaic Ungulata.

Each chapter contains a systematic table using linnaean taxa and a hierarchy of systematic units following Malcolm McKenna and

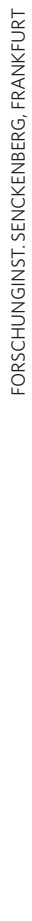


Susan Bell's book Classification of Mammals (Columbia University Press, 1997). But the PhyloCode (www.ohio.edu/phylocode) - a set of rules governing phylogenetic nomenclature that in recent years has gained many proponents among zoologists and palaeontologists
- is not mentioned in the book. In the final chapter, Rose provides a summary of the idea of a sudden explosion of mammals after the Cretaceous-Tertiary boundary.

This beautiful and thorough book will be an essential tool for all those who work on fossil and extant mammals, and for both advanced undergraduate and graduate students. It is a 'must buy' for palaeontological libraries. Zofia Kielan-Jaworowska is at the Institute of Paleobiology, Polish Academy of Sciences, Warsaw, Poland.

\section{Mysteries of female anatomy}

\section{Secrets of Women: Gender, Generation, and the Origins of Human Dissection by Katharine Park \\ Zone Books: 2006.300 pp. \$36.95}

\section{Rina Knoeff}

Although the history of dissection in general has received increasing attention, the importance of anatomizing female bodies has hitherto been neglected. Katharine Park's Secrets of Women is a first attempt to fill the gap. She relates a fascinating history of women on the dissection table. Central to her book are the almost unbelievable stories of an abbess whose heart contained a cross, a crown of thorns, nails and a lance, items well known as symbols of the Passion of Christ; the investigation of the body of a lactating virgin prophetess; the search for the cause of death of patrician wives and mothers; and the dissected body of an executed female criminal. The accounts are bizarre yet captivating, as they portray the opening of the body not only as a medical procedure, but also as a cultural practice embedded in religious and social life. Park also exposes the myths that in the wake of Pope Boniface VIII's bull Detestande feritatis in 1299, the opening of bodies was surrounded by a cultural taboo, and also that anatomical practice was primarily a male practice studying male bodies.

Park argues that from the mid-thirteenth to the mid-sixteenth century, Italians understood their bodies both in terms of religion and in relation to family and kinship, and that this particular way of viewing the body shaped dissection practices. Male uncertainty regarding fatherhood (were they really the fathers of their children?), the existence of female-only knowledge regarding sexuality and generation (mainly related to inordinate sexual appetite, abortion practices, the exercise of sexual autonomy and the exertion of power over men), as well as the functioning of the reproductive system inside the female body, culminated in an excessive interest in what came to be known as 'the secrets of women'. As a result, Park argues, the uterus (and hence the inside of the female body) became a focal point of anatomical research in Italian patriarchal society.

Related to the opening of mothers' bodies, dissection practices concentrated on holy women. Not only did women manifest religious experiences in a particular corporeal way, but these experiences were also described in physiological terms of pregnancy. It was, for

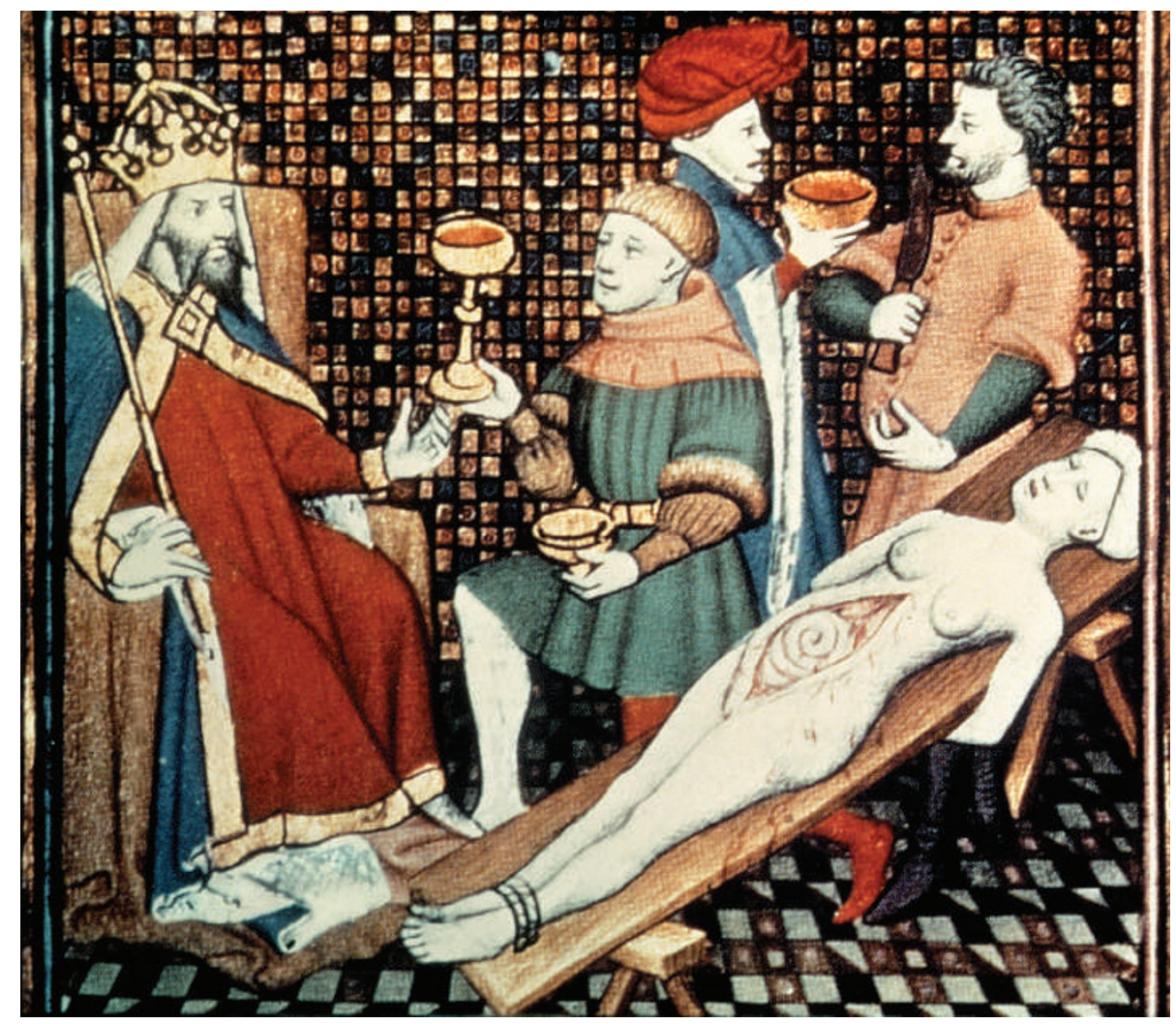

The dissection of female bodies had religious and familial significance in the fifteenth century.

instance, believed that Christ's presence in the heart would create new life in the same way as the father's seed in the mother's uterus. According to Park, the themes of holiness, generation and female corporeality together contributed importantly to the history of dissection.

At times, however, Park's interpretation is merely suggestive and the historical proof wafer-thin. For instance, her argument that holy women generate relics much as mothers generate children is well argued. But her suggestion that the dissection of holy women in order to extract relics can be viewed as a religious variant of a caesarean section, in which a baby was removed from a dead mother's body so it could be baptized, seems far-fetched.

In a similar vein, Park's understanding of religion is sometimes rather naive. Her interpretation of Christianity as exclusively Roman Catholic is understandable given the Italian context she describes, but it leaves no room for a pluralist view of religion. For Park, depictions that lack characteristically Roman Catholic symbols don't seem to count. For example, she interprets the frontispiece of Andreas Vesalius' book on human anatomy De humani corporis fabrica as secular, simply because there are no Catholic icons. Yet, particularly given Vesalius' Protestant upbringing, it can, and perhaps should, be viewed as a Protestant depiction (as other historians of medicine have done before).

Nevertheless, Park's book will undoubtedly prove to be an important contribution to the history of anatomy. For the first time it extensively discusses the history of anatomy from the viewpoint of the corpse and, because of its particular focus on women's bodies, it will radically change the way we think about the (male) history of the anatomized body. As such, the book is a 'must read' for anyone working on the history of pre-modern medicine. But because of its lucid style and fascinating argument, it is also surprisingly accessible, and I recommend it to anyone interested in the history of anatomy.

Rina Knoeff is in the Faculty of Arts, University of Leiden, 2300 RA Leiden, the Netherlands. 